\title{
EXPERIMENTAÇão Nas Aulas de Química de um CuRso PRÉ-Vestibular: UM RELATO DE EXPERIÊNCIA
}

\author{
EXPERIMENTATION IN THE CHEMISTRY CLASSES OF A PRE-VESTIBULAR \\ COURSE: AN EXPERIENCE REPORT
}

DOI: $\underline{\text { 10.23926/RPD.2526-2149.2020.v5.n2.p1155-1170.id752 }}$

\section{José Víctor Acioli da Rosa \\ Especialista em Docência do Ensino Superior (FAVENI) \\ victoracioly.va@gmail.com}

\section{Gahelyka Aghta \\ Pantano Souza}

Doutoranda em Educação

(UFPR)

Professora na Universidade

Federal do Acre (UFAC)

gahelyka@outlook.com

\section{Francisca Georgiana \\ Martins do \\ Nascimento \\ Mestre em Ensino de \\ Ciências e Matemática \\ (MPECIM/UFAC) \\ Professora no Instituto \\ Federal do Acre (IFAC) \\ regiana.tavares@gmail.com}

\section{André Ricardo \\ Ghidini}

Doutor em Biologia de Água

Doce e Pesca Interior

(INPA)

Professor na Universidade

Federal do Acre (UFAC)

andre.ghidini@ufac.br
Resumo: As aulas experimentais surgem como uma estratégia eficiente devido ao seu caráter motivador. Em um curso preparatório para Exames e Vestibulares, destaca-se o ensino de uma gama de conteúdos em pouco tempo. Nesse contexto, este trabalho visa investigar as contribuições e as limitações da utilização da experimentação em aulas de Química de um curso pré-vestibular em Rio Branco/Acre. Com abordagem metodológica de pesquisa qualitativa do tipo exploratória, utilizou-se, na produção dos dados, um questionário semiestruturado, aplicado após 17 encontros, sendo que em cada encontro foram realizados diferentes experimentos demonstrativos. Os resultados indicam que a utilização da experimentação contribui para motivar e incentivar a participação dos alunos na aula e que estes justificam essa importância por considerarem que a explicação fica mais clara. Contudo, no que se refere às limitações, os discentes apontam pouca carga horária e espaço não adequado, afirmando não ser uma modalidade de ensino tradicionalmente esperada em cursinhos preparatórios.

Palavras-chave: Ensino de Química. Experimentação Demonstrativa. Curso Pré-Vestibular.

\begin{abstract}
Experiemental classes constitute in an efficient teaching strategy due to their motivating nature. On a preparatory course for Exams and "Vestibular" exams, the teaching of a wide range of contents in a short period of time stands out. In this context, this work aims to investigate the contributions and limitations of the use of experimentation in Chemistry classes of a pre-university course in Rio Branco/Acre. With a qualitative and exploratory research approach, a semi-structured questionnaire was used in the collection of data, applied after 17 classes, and in each one, different demonstrative experiments were carried out. The results indicate that the use of experimentation contributes to a better understanding of the subject and their concepts and the students justify this importance, considering that the explanation becomes clearer. However, regarding the limitations, the students pointed out insufficient course load and inadequate space, stating that this type of teaching method is not traditionally expected in preparatory classes.
\end{abstract}

Keywords: Chemistry teaching. Experimentation. Pre entrance exam. 


\section{INTRODUÇÃO}

A experimentação é um recurso importante no ensino de Ciências e que surge no começo do desenvolvimento da Ciência Química, quando ela ainda era considerada Alquimia. Nessa época, os alquimistas buscavam encontrar a "pedra filosofal" e o "elixir da longa vida". Com base nessa ideia e busca, tem início o processo de experimentação alquímica (LOPES, 2013), com suas práticas e manuseios de substâncias.

Diversas são as metodologias para o ensino experimental, porém, de acordo com Araújo e Abib (2003), destacam-se as do tipo Demonstrativa e as do tipo Investigadora/problematizadora. $\mathrm{Na}$ abordagem do tipo demonstrativa, o professor assume o papel principal frente à sala de aula, demonstrando e focando nos pontos que merecem ser observados e destacados na atividade. Nessa proposta, as práticas demandam um menor tempo de realização, tentando contemplar todos os alunos com a demonstração.

No ensino praticado por meio das experimentações investigativas, os alunos são os "pequenos pesquisadores", de modo que eles têm a possibilidade de desenvolver as habilidades de observar, investigar, manipular e divulgar. Tal enfoque, nesse tipo de experimentação, está na busca por desenvolver nos alunos competências e habilidades que envolvam aspectos como "relacionar, decidir, planejar, propor, discutir, relatar", contrariando os tipos de experimentações tradicionais, chamadas de "receitas de bolo" (FERREIRA et al, 2010).

As aulas de Química, por sua vez, devem considerar a importância de se integrar a experimentação ao ensino, com boa aceitação por parte dos professores e alunos, tendo em vista que a aula prática, como é tradicionalmente conhecida a experimentação nas escolas, é um importante recurso para a aprendizagem que pode auxiliar os alunos no entendimento de fenômenos e na construção dos conceitos.

Estudar Química não consiste em decorar fórmulas ou fazer cálculos matemáticos, mas, sim, estudar a constituição e a transformação da matéria, explicando fenômenos do cotidiano por meio das práticas experimentais (ÁVILA; MATOS, 2017). Nesse sentido, à medida que aumenta o desejo por parte dos estudantes de ingressarem nos cursos de nível superior, surgem os cursos preparatórios, onde se propõem aulas que objetivam ampliar as chances de ingresso, principalmente, em universidades públicas e, quase sempre, para os cursos de maior concorrência.

Dentro desse contexto, esta pesquisa propôs como objetivo investigar as contribuições e as limitações da utilização da experimentação em aulas de Química de um curso pré-vestibular em Rio Branco/Acre. Essa temática foi escolhida pelo fato de encontrarem-se, nesses cursos, 
alunos advindos de escolas públicas e particulares, que não têm tanta familiaridade com aulas práticas.

\section{O Ensino De Química no Contexto De Cursos De Pré-Vestibulares}

Com o interesse pelo ensino superior aumentando, surgiram, também, os cursos preparatórios para os exames vestibulares, normalmente, frequentados por jovens e adultos que objetivam ampliar suas chances de ingresso em universidades públicas. Na sua maioria, os cursos são de natureza privada, poucos são os de natureza pública, capazes de atender a parte da população de menor poder aquisitivo (BARONI, 2010).

Os cursos pré-vestibulares, de um modo geral, proporcionam a revisão de todos os conteúdos já estudados nos três anos do Ensino Médio, com foco nos conteúdos mais recorrentes nas provas e, assim, visam preparar os alunos para os exames seletivos (OLIVEIRA et al, 2013). Para Whitaker (2010), essa modalidade de ensino aponta limitações do sistema de ensino regular em preparar seus jovens para as provas de ingresso nas instituições de ensino superior, tanto para os que cursaram o Ensino Médio nas escolas públicas quanto para aqueles que vieram do ensino privado.

Entre os vários traços que permeiam o ensino de Química, no contexto de um curso preparatório para o Exame Nacional do Ensino Médio, destaca-se o ensinar uma gama de conteúdos teóricos, cálculos matemáticos e a utilização do raciocínio lógico em função do pouco tempo de aula (SANTOS; FERREIRA, 2016), o famoso “3 anos em 1", que consiste em ensinar os conteúdos das três séries da estrutura curricular do Ensino Médio em apenas um ano corrido, amontoando um item após o outro. Outro aspecto importante, vale salientar, é que muitas das questões, principalmente nas Ciências da Natureza e suas Tecnologias/Química, deveriam ser contextualizadas, contudo, são, na sua maioria, apenas questões relacionadas ao cotidiano do aluno. Além de o conteúdo ser extenso, precisa ser potencializado o entendimento de questões contextualizadas ou relacionadas ao cotidiano, sem que, muitas vezes, o aluno tenha tido contato com esse tipo de raciocínio em sala de aula.

Stadler et al (2020) discutiram as transformações do currículo, com especial destaque para a Base Nacional Comum Curricular (BNCC), considerando, inclusive, a concentração de conteúdos de Química na área de Ciências da Natureza e suas Tecnologias. Porém, com a consequente redução das competências e habilidades a serem trabalhadas nessa área, tal reformulação destoa qualitativamente do que tradicionalmente tem sido observado no Exame Nacional do Ensino Médio (ENEM), embora esperem-se mudanças nos próximos ciclos. 
Ao descrever sobre a escolha das estratégias de abordagens dos conteúdos, nos cursos pré-vestibulares, Whitake $(2010$, p. 2) considera que tais estratégias são as mais "antipedagógicas possíveis", por estarem ligadas à memorização pura e simples, sem tempo para debates, reflexões, críticas e mobilização dos esquemas de assimilação. Destaca-se, ainda, o fato de que os professores inventam formas sensacionalistas para prender a atenção dos alunos com aulas consideradas "shows", uso de dicas, "macetes" e repetição de fórmulas químicas em ritmos de paródia (TONDIN et al, 2017, p. 11).

Na maioria das vezes, o "cursinho" disponibiliza o material didático, bem como outros recursos a serem trabalhados, na expectativa de que o professor construa um ensino que propicie os melhores meios para que o aluno seja capaz de utilizar conceitos, fórmulas e conteúdos nos exames seletivos (SANTOS, 2004). Contudo, o que se percebe é que a prática pedagógica dos professores de cursos preparatórios é, quase sempre, compreendida como uma "salvação" (TONDIN et al, 2017, p. 10), já que promove aulas dinâmicas e descontraídas, apesar do cunho conteudista e de memorização de conceitos, como afirmam Tapia e Fita (2006).

Tal contexto vem construindo uma imagem dualista entre o professor das escolas regulares e o professor dos cursos pré-vestibulares. Os professores das escolas regulares seguem as atividades previstas para o ano letivo conforme a série de ensino em que atua, podendo ou não, em alguns momentos, desenvolver aulas com foco específico nos exames de seleção universitária. Enquanto os professores dos cursos pré-vestibulares são definidos por Chassot (2004) como de "pedagogias fast foods", marcadas pela necessidade imediata de alterar as posições de desenvolvimento de seus alunos no vestibular (2004). Essa dualidade também transparece na imagem que é estabelecida em relação à escola, posta como "ineficiente" quando comparada aos cursinhos, especialmente, pelo caráter "dinâmico" com que estes são apresentados perante a sociedade, desconsiderando totalmente a profunda distinção dos objetivos de cada espaço perante a formação do cidadão (TONDIN et al, 2017).

Como ciência, a Química "tem como objetos de investigação as propriedades, a constituição e as transformações dos materiais e das substâncias" (MORTIMER; MACHADO, 2016, p. 296). Nos avanços quanto à experimentação, entende-se que estudar Química não é apenas decorar fórmulas ou fazer cálculos matemáticos, mas, sim, estudar a constituição e a transformação, estabelecendo relações com fenômenos do cotidiano (ÁVILA; MATOS, 2017).

Em contraponto ao uso de aulas formais ou "tradicionais" (CASTAMAN; VIEIRA, 2013, p. 3), realizadas no cotidiano das escolas, as aulas experimentais surgem como saída do "clássico", despertando forte interesse nos alunos, especialmente, devido ao seu caráter 
motivador e lúdico (GIORDAN, 1999). Esse tipo de aula tem uma dimensão de aprendizagem, uma vez que pode servir como uma estratégia eficiente para a contextualização de conceitos isolados no cotidiano dos alunos (GALIAZZI; GONÇALVES, 2004).

Há quem atribua ao sistema de ensino a responsabilidade pelas atividades experimentais raramente serem realizadas ou pela falta de tempo com a grande demanda dos conteúdos e com o alto "custo de materiais e instrumentos. Há, ainda, o fato de que alguns professores utilizam as atividades experimentais de forma desarticulada das aulas teóricas, não contribuindo, desse modo, para uma aprendizagem significativa" (FREITAS-FILHO et al, 2012, p. 85).

Silva e Machado (2008) ressaltam que não se faz necessário um laboratório para haver experimento. Aparelhos acessíveis e baratos, até mesmo "sucatas", podem virar materiais de uma aula experimental. Flores, folhas e álcool podem ser transformados em indicadores, já que apenas mencionar "indicadores nas aulas é muito pouco, quando comparado com o impacto cognitivo que causa se for mostrada a mudança de cor em diferentes meios" (USBERCO; SALVADOR, 2011, p. 15). Os laboratórios virtuais também são importantes ferramentas para o desenvolvimento de práticas experimentais, sem a estrutura física do laboratório (LUCENA et al., 2013).

A ideia de desenvolver atividades experimentais sem a necessidade do espaço específico, o laboratório devidamente equipado, é defendida por Chaves e Hunsche (2014), segundo eles, existem atividades experimentais que podem ser desenvolvidas em qualquer sala de aula, em pátios ou ambientes propícios para o manuseio de materiais simples e de baixo custo e, qualquer que seja o método de ensino-aprendizagem utilizado, este deve mobilizar o aprendiz.

Para Gioppo et al. (1998), não necessariamente a inserção da experimentação propiciará a aprendizagem, mas, sim, "a maneira como a experimentação é realizada e sua integração no conteúdo são mais importantes que a própria experimentação” (GIOPPO et. al., 1998, p. 45). Segundo Maldaner, quando a "química experimental não é refletida tende a ser igual à química de quadro e giz, ou até pior, porque vai perdendo mais tempo. O importante é a discussão, a reflexão" (MALDANER, 2003, p. 252).

Para que os experimentos tenham importância no desenvolvimento cognitivo dos alunos, precisam se integrar a uma sequência de outras atividades, de forma que provoquem reflexões e discussões de ideias, dando sentido aos conceitos abordados (NOVAIS; TISSONI, 2016). Existem diferentes abordagens para a aplicação de aulas experimentais no ensino de Química, a experimentação pode ser conduzida de diferentes formas. Tradicionalmente, o aluno 
segue um roteiro experimental, tipo "receita de bolo", porém, há a experimentação do tipo ilustrativa/demonstrativa e do tipo investigativa/problematizadora (OLIVEIRA, 2010). No entanto, fica a critério do professor a melhor estratégia de experimento diante do conteúdo e dos objetivos da aula.

Chaves e Hunsche (2014) apontam para a importância do uso de atividades experimentais em sala de aula, já que estas podem possibilitar ao aluno o manuseio dos materiais a serem utilizados, tornando-os ativos no processo de ensino-aprendizagem, por meio da experimentação investigativa, ou, ainda, das atividades experimentais demonstrativas, por conduzirem os alunos à compreensão da teoria estudada, por meio da observação.

A aprendizagem dos estudantes a partir do uso de atividades experimentais possui relação com a forma com que o professor expõe a prática e a teoria. Ainda assim, com o uso da experimentação, é possível que os estudantes percebam as atividades como eventos isolados, apenas com o simples objetivo de chegar à resposta certa. Para isso, quanto mais próximas da realidade cultural do aluno forem as atividades, mais significativas se tornarão no processo de ensino-aprendizagem. As atividades experimentais podem ser organizadas de várias maneiras, conforme objetivo e necessidade do professor, tendo, assim, características diferentes (CHAVES; HUNSCHE, 2014).

\section{Metodologia}

Nos moldes de uma pesquisa de natureza qualitativa, do tipo exploratória descritiva, método frequentemente empregado no intuito de se "familiarizar com os fenômenos surgidos durante a pesquisa, explorando os próximos passos mais profundamente e com maior precisão" (PRAÇA, 2015, p.75), desenvolveu-se este trabalho. Independentemente da área, o método exploratório é utilizado, com frequência, em pesquisas de "natureza social e cultural" (PRAÇA, 2015, p.82), assim como no estudo de caso "do desejo de entender fenômenos sociais complexos" (YIN, 2015, p.4). Portanto, no contexto deste trabalho e dos percursos metodológicos utilizados, optou-se por um estudo baseado em questionários, observação e levantamento de dados (PRAÇA, 2015, p.80.)

Para a coleta de dados, utilizou-se como instrumento o questionário semiestruturado, sendo este considerado um dos instrumentos mais comuns de coleta de dados ou até mesmo de informações importantes, podendo ser organizado em diferentes divisões, com perguntas abertas, fechadas ou mistas (MARCONI; LAKATOS, 2010). Nesta pesquisa, o questionário utilizado foi organizado em três blocos e aplicado, após a realização de todas as aulas 
experimentais, para os alunos de curso pré-vestibular, contexto desta pesquisa. O instrumento foi aplicado após 17 encontros de 100 minutos, em cada encontro foi realizado um experimento diferente, totalizando 16 experimentos, que abordavam diferentes conteúdos e seus conceitos, como: Densidade, Forças Intermoleculares; Funções Inorgânicas; Reações Químicas; Estudo dos gases; Soluções; Termoquímica; e Cinética Química.

Alguns princípios éticos foram considerados na realização da pesquisa, os participantes foram convidados a participar voluntariamente, foram informados de que poderiam desistir da participação a qualquer momento sem ônus ou prejuízos, conforme o Termo de Consentimento Livre Esclarecido (TCLE). Foram informados, também, de que não teriam seus nomes ou qualquer tipo de identificação revelados.

Para preservar os participantes da pesquisa, foram utilizados nomes fictícios, optou-se pelos nomes propositalmente escolhidos de acordo com os elementos da tabela periódica, seguindo a sequência por número atômico. A designação do elemento químico atribuído a cada participante da pesquisa não faz alusão ao seu gênero.

\section{Resultados}

Os resultados desta pesquisa estão apresentados a seguir e foram organizados conforme as etapas adotadas na elaboração do questionário semiestruturado. Dessa forma, dividiu-se esta seção em dois momentos de análise: Perfil Socioeconômico e Experimentação em cursos prévestibulares.

\subsection{Bloco 1 - PeRfiL SocioeconôMICo}

Participaram deste estudo 30 alunos matriculados em um curso pré-vestibular de Rio Branco/Acre, com idades que variaram de 15 a 28 anos, sendo 14 participantes do sexo feminino e 16 do sexo masculino. Ao serem questionados sobre qual a ocupação profissional que desempenhavam, apenas $7 \%$ responderam que exercem atividade remunerada, enquanto 93\% dedicam-se exclusivamente aos estudos.

Em relação ao tipo de instituição de ensino onde cursaram ou estariam cursando o Ensino Médio, 57\% declararam terem estudado ou ainda estarem estudando em escolas públicas. De acordo com Whitaker (2010), a escolha pelos cursos pré-vestibulares ocorre devido às limitações do sistema de ensino regular, principalmente, do sistema público de ensino, no preparo de seus alunos para os exames de seleção das universidades públicas. Pouco menos da metade dos participantes da pesquisa, $40 \%$, estão cursando ou cursaram o Ensino Médio em escolas privadas, outros $3 \%$ não responderam. 
Foi perguntado aos participantes qual o curso universitário que eles desejam cursar. O mais citado foi "Medicina", com 47\%, seguido pelos cursos de "Direito" e "Nutrição", com $23 \%$ e $10 \%$, respectivamente. Os outros $20 \%$ correspondem aos cursos menos citados, que foram: "Enfermagem"; "Engenharia Civil"; "Medicina Veterinária" e "Filosofia".

Para Vargas, as respostam indicam cursos de "status" e "prestígio na sociedade" (VARGAS, 2010, p.110), cursos que, muitas vezes, são apresentados para os alunos ainda na idade infantil, pelos pais e/ou sociedade, por se tratarem de formações para o exercício de profissões bem vistas, bem valorizadas e bem remuneradas.

Nesse sentido, esses alunos acreditam que os cursos pré-vestibulares irão ajudá-los no processo de seleção para cursos universitários tão concorridos, já que serão melhor preparados, em outras palavras, a maioria dos alunos de cursos pré-vestibulares busca ingresso em cursos de alta concorrência.

A dinâmica das aulas, focadas em resolução de problemas, a seleção dos conteúdos que mais são vistos no Exame Nacional do Ensino Médio, a presença de material didático específico e recursos audiovisuais, aliadas à presença de professores especializados em aulas mais dinâmicas, lúdicas e agitadas estão entre os principais motivos para os estudantes procurarem os cursos preparatórios, para além do Ensino Médio tradicional (TONDIN et al, 2017).

\subsection{BLOCO 2 - EXPERIMENTAÇÃo EM CURSOS Pré-VeSTIBUlaReS}

Neste bloco, buscou-se compreender as contribuições da utilização da experimentação no curso pré-vestibular, durante as aulas de Química. Inicialmente, foi questionado aos participantes quais seriam as suas concepções a respeito da utilização da experimentação nas aulas de Química do "cursinho" e se para o ensino intensivo em cursos pré-vestibulares era viável o uso desse tipo de abordagem.

Todas as respostas dos participantes da pesquisa foram "Sim”, por considerarem viável o uso da experimentação como recurso didático. Em suas palavras, os participantes consideram que as aulas experimentais são:

\footnotetext{
-Claras e explicativas, ajudam o entendimento do conteúdo com elementos e hábitos do cotidiano - (Neônio).

-Interessante. Pois nos tira das rotinas das aulas tradicionais - (Sódio).

-Considerando o fato de que o ENEM apresenta muitos experimentos, é muito importante - (Berílio).

-Eu aprovo, pois acredito que a aula se torna mais interessante. Os alunos interagem e participam - (Carbono).

-Boas, pois tira as pessoas da rotina de só fazer cálculos - (Zinco).
} 
Entretanto, mesmo que para todos os alunos a experimentação seja uma prática importante nas aulas do curso pré-vestibular, e justifiquem essa importância, considerando que a explicação fica mais clara, alguns participantes não concordam com a utilização desta, conforme evidenciado nos depoimentos a seguir:

\footnotetext{
-Às vezes demorada, tendo em vista que no "cursinho" a carga horária é menor (Níquel).

-Dependendo da matéria, pode atrapalhar, pois temos um tempo muito reduzido para rever toda a matéria que, em tese, já era para os alunos saberem... Facilita, apesar de poder atrasar o cronograma pela questão do tempo - (Cromo).
}

Apesar da experimentação utilizada nas aulas do "cursinho" ser do tipo demonstrativa, realizada apenas com o intuito de elucidar a teoria discutida, percebe-se que tal prática nem sempre é bem recebida pelos alunos, principalmente, por essa não ser uma ação comum nos cursos pré-vestibulares, já que, quase sempre, a metodologia de ensino, nesses espaços, é a mais mecânica possível, com vícios e defeitos, decorrentes de uma carga muito grande de conteúdos, em que se pede para o aluno decorar e repetir (SCHWARTZMAN, 2010).

Vale ressaltar que os estudantes, durante os diversos experimentos realizados, apresentaram interesse em observar os fenômenos, faziam perguntas a respeito do que observavam enquanto as reações ocorriam. Pareciam satisfeitos, inclusive, os que justificaram não achar adequada a utilização de atividades práticas nas aulas do "cursinho". Porém, compreende-se a resposta do participante Cobre ao considerar que atividades experimentais não fazem parte das aulas de um curso pré-vestibular.

Há nos cursos pré-vestibulares a utilização de um material disponibilizado pelo próprio "cursinho" e cabe ao professor trabalhar com a turma esse material, no qual estão relacionados inúmeros conteúdos teóricos, cálculos matemáticos e de raciocínio lógico para serem abordados dentro de um cronograma pré-definido. Observando a grande demanda de conteúdos em detrimento do pouco tempo para o desenvolvimento, talvez seja mais apropriado dizer que o "estilo do "cursinho" seja aquele em que o aluno "aprenda para ser aprovado", ele é treinado em resolver questões de maneira monótona e repetitiva. Qualquer modo de abordagem diferente disso torna-se "Desnecessário, pois o tempo que é gasto nesses experimentos poderia ser investido em algo mais eficaz - (Magnésio)", mesmo que proporcione um efeito positivo no processo de ensino-aprendizagem, especialmente, no que diz respeito à importância da experimentação para o desenvolvimento do raciocínio lógico e factual, constituintes essenciais dos itens do ENEM (BEVILACQUA; COUTINHO-SILVA, 2007). 
Os participantes da pesquisa foram questionados a respeito do nível de dificuldade presente nos experimentos realizados, sobre quanto difícil poderiam ser e, ainda, se eles, como alunos, conseguiriam reproduzir os mesmos experimentos em casa. Em suas respostas, destacaram que não havia dificuldade nos experimentos:

-Não, ele desenvolve métodos para que se torne fácil - (Carbono).

-Não, pois podem ser feitos em casa - (Zinco).

-Não, pois o professor busca facilitar os experimentos de modo que o aluno entenda - (Magnésio).

-Não, são sempre de fácil execução e aprendizagem - (Fósforo).

-Não, são coisas que utilizamos no dia a dia - (Hidrogênio).

-Não, são usados métodos cotidianos e objetos casuais que deixam as aulas dinâmicas - (Neônio).

Em seguida, foi questionado aos alunos sobre os possíveis pontos negativos e positivos do uso de experimentação nas aulas do curso pré-vestibular. 56,6\% disseram não haver nenhum ponto negativo, pelo contrário, acham a atitude do professor “[...] inovadora" - (Carbono), como se pode observar nas respostas a seguir:

-O indivíduo absorve mais aprendizado - (Magnésio).

-Participação dos alunos, método de desenvolvimento mais fácil - (Carbono).

-Clareza, dinamicidade, diversidade no método de ensino e concentra a atenção dos alunos - (Neônio).

-É bom pois facilita a aprendizagem do aluno como também o raciocínio lógico (Alumínio).

-Sair da rotina de só pinceis e quadro - (Zinco).

-Melhor compreensão do conteúdo passado pelo professor - (Oxigênio).

Por outro lado, 43,4\% dos participantes afirmaram haver pontos negativos, como nas justificativas a seguir:

-Ocupa o tempo que poderia ser utilizado na continuação do conteúdo de exercícios (Potássio).

-O local não é muito adequado - (Boro).

-Apenas a sujeira - (Cobalto).

-A questão do tempo perdido que poderia ser aproveitado de outras formas. (Cromo).

-Na minha concepção, os experimentos, muitas vezes, se tornam uma perda de tempo - (Magnésio).

Observa-se, nas respostas dos estudantes, posicionamentos que apontam para a necessidade de espaços adequados na realização da experimentação, seja ela demonstrativa ou investigativa/problematizadora. Resposta como: "O local não é muito adequado. - [Boro]" 
remete à compreensão de haver a necessidade de um laboratório para que as aulas experimentais possam ser realizadas (SILVA e MACHADO, 2008).

Ao final do questionário foram solicitadas aos alunos sugestões de outros recursos didáticos que poderiam ser utilizadas nas aulas de Química, que fossem além da experimentação demonstrativa. As respostas foram relacionadas no Quadro 1, a seguir:

Quadro 1 - Sugestão de Métodos que facilitam a aprendizagem

\begin{tabular}{|c|c|}
\hline RECURSOS DIDÁTICOS & $\begin{array}{c}\text { QUANTIDADE DE VEZES } \\
\text { REPETIDA }\end{array}$ \\
\hline Aula de Campo & 07 \\
\hline Paródia & 05 \\
\hline Vídeos & 02 \\
\hline Animações Gráficas & 02 \\
\hline Utilização de laboratórios de Química & 02 \\
\hline O uso de comida nas aulas & 01 \\
\hline Lando exemplos relacionados ao dia a dia do aluno & 01 \\
\hline Livros com ilustrações & 01 \\
\hline Aulões & 01 \\
\hline Oficinas Intensivas & 01 \\
\hline Aulas mais envolventes com os alunos & 01 \\
\hline Não sei & 08 \\
\hline
\end{tabular}

Fonte: Os autores.

As respostas dos estudantes transitam, principalmente, entre recursos que são tradicionalmente usados nos cursos preparatórios (paródias, vídeos, animações), embora a aula de campo tenha sido a mais apontada pelos estudantes, contrastando com a ideia desses alunos sobre o ensino típico esperado nos cursinhos. Nota-se, também, uma preferência dos estudantes por recursos pedagógicos passivos de ensino-aprendizagem, influência do sistema de ensino ainda fortemente marcado pelos métodos tradicionais de transmissão de conteúdo, onde há a relação unidirecional entre professor-aluno (DIESEL et al, 2017).

Além da sugestão de recursos didáticos, solicitou-se, ainda, que os alunos apresentassem sugestões de experimentos que eles gostariam que fossem realizados nas aulas de Química do curso pré-vestibular. As repostas foram relacionadas no Quadro 2, a seguir:

Quadro 2 - Sugestão de Experimentos para realização nas aulas de Química do curso pré-vestibular

\begin{tabular}{|c|c|}
\hline EXPERIMENTOS SUGERIDOS & QUANTIDADE DE VEZES REPETIDA \\
\hline Pilhas Caseiras & 01 \\
\hline Destilação Fracionada & 01 \\
\hline Ácidos & 01 \\
\hline Gases & 01 \\
\hline Adoção de animações em 3D & 01 \\
\hline Equilíbrio Iônico & 01 \\
\hline O uso de Pólvora & 01 \\
\hline Não sei & 25 \\
\hline
\end{tabular}

Fonte: Os autores. 
No Quadro 2, destaca-se que, por 25 vezes, os participantes da pesquisa não souberam indicar propostas de experimentos a serem realizados em aulas futuras, o que possibilita inferir que a experimentação, ainda que demonstrativa, não fez parte da formação escolar desses estudantes. Isso, provavelmente, deve-se ao fato de que $57 \%$ dos participantes da pesquisa foram ou ainda são alunos da escola pública, reforçando as estatísticas que afirmam quão difícil é para os professores da rede pública de ensino realizarem aulas experimentais (LIMA et all, 2016).

Para Araújo; Abib (2003), as atividades experimentais demonstrativas quase sempre demandam um pequeno tempo de realização e podem ser facilmente integradas à aula, seja no início, no final ou como aula de revisão. Nesse sentido, as atividades experimentais realizadas no curso pré-vestibular seguiram o mesmo princípio de organização proposto pelos autores, conseguindo despertar na maioria dos alunos o interesse pelo tema e conteúdo abordados, como evidenciado na fala do discente Carbono, que afirma: "As aulas motivam a participação dos alunos".

De maneira geral, os resultados indicam que o uso de experimentação em aulas de Química no contexto de um curso pré-vestibular contribuiu para motivar e despertar o interesse dos alunos nas aulas de Química. O uso da experimentação, segundo Silva (2016), pode ser relacionado ao fato de que pode integrar o conhecimento teórico à comprovação de leis e contribuiu, mesmo no contexto do pré-vestibular, através do estímulo da resolução de situações problemáticas levantadas pelo professor. Porém, foram observadas limitações, como apontado por alguns participantes, ao alegarem que a experimentação, apesar de interessante, configurase como uma situação incomum na rotina de um "cursinho". Contudo, a aceitação e compreensão dos conteúdos por meio da utilização de experimentos foram observadas na maioria dos partícipes da pesquisa.

\section{CONSIDERaÇões FinaIS}

Ao concluir-se esta pesquisa, retorna-se ao problema que a originou: "Como a experimentação contribui para as aulas de Química de um curso pré-vestibular em Rio Branco/Acre?”. A partir do estudo realizado, compreendeu-se que a experimentação é um recurso importante nas aulas de Química, e isso independe do contexto onde ela é empregada. As atividades experimentais do tipo demonstrativas, realizadas no curso pré-vestibular, contribuíram com as aulas de Química, ainda que tal recurso fosse considerado, por alguns alunos, como fora de contexto para um "cursinho". 
A partir da pouca experiência como professores em curso pré-vestibular e observando as dificuldades que se tem em ensinar conceitos químicos, os pesquisadores sentiram-se motivados a "inovar" na tentativa de melhor abordar os conceitos que envolvem conteúdos de Química em um “cursinho". Assim, optou-se por uma abordagem experimental que buscasse relacionar o cotidiano dos alunos aos conceitos abordados nas aulas e explicar os conteúdos mais cobrados pelos exames de vestibulares e ENEM. A Experimentação Demonstrativa associada à utilização de materiais de fácil acesso e baixo custo apresentou-se como uma prática promissora para esse contexto de ensino, principalmente, por motivar e estimular o interesse do aluno pelos conceitos abordados.

Compreende-se que a experimentação em cursos pré-vestibulares não é comum, o que justifica as dificuldades em encontrar materiais e produções científicas na literatura, disponíveis na internet, para a utilização de novas abordagens de ensino em "cursinho", principalmente, no que se refere à experimentação nesse contexto. Durante todas as atividades experimentais propostas e realizadas nas aulas do curso pré-vestibular, percebeu-se um real envolvimento dos estudantes nas temáticas relacionadas às práticas. Por vezes, notava-se, nas primeiras aulas, uma certa resistência quanto ao uso de experimentos. Essa, por sua vez, foi diminuindo com o passar dos dias, diante dos variados experimentos demonstrativos utilizados, e da relação destes com os conteúdos. Dias após a conclusão do planejamento proposto para aulas experimentais, os alunos chegaram a questionar os motivos pelo quais as aulas não tinham mais experimentação.

A metodologia utilizada no curso para abordar diferentes conteúdos despertou um forte interesse, por parte dos estudantes, em continuar com os experimentos, fazendo com que os repetissem em casa (como houve relatos). As atividades práticas apresentadas e discutidas ao longo das aulas fizeram com que alguns alunos sugerissem um espaço exclusivo ou ainda um laboratório para realização das aulas experimentais e de novos experimentos na área de Química ou demais áreas.

Os resultados indicaram algumas limitações, que dificultaram o processo de realização das atividades experimentais nos cursos pré-vestibulares. Limitações estas compreendidas em três causas específicas, a saber:
a) Não fazer o estilo do "cursinho";
b) Não haver um espaço adequado;
c) Pouca carga horária. 
Alguns desses entraves podem motivar pesquisas futuras no contexto dos cursos prévestibulares, enquanto outros podem mobilizar discussões no contexto das aulas de química da educação básica, uma vez que a experimentação é uma prática pouco recorrente em aulas de Química, principalmente em escolas da rede pública de ensino.

\section{REFERÊNCIAS}

ARAÚJO, Mauro Sérgio Teixeira de.; ABIB, Maria Lúcia Vital dos Santos. Atividades experimentais no Ensino de Física: diferentes enfoques, diferentes finalidades. Revista Brasileira de Ensino de Física, São Paulo - Brasil, v. 25, n.2, p. 176-194, 2003.

ÁVILA, Simone Garcia.; MATOS, Jivaldo do Rosáriz. Compostos coloridos do ferro: uma proposta de experimentação utilizando materiais de baixo custo. EDUCACIÓN QUÍMICA, v. 28, p. 254-261, 2017.

BARONI, José Marcelo Biagioni. Acesso ao ensino superior público: realidade e alternativas. 2010. Tese (Doutorado em Educação) - Faculdade de Educação, Universidade de São Paulo, São Paulo, 2010. DOI: 10.11606/T.48.2010.tde-20042010-112755. Acesso em: 2018-10-31.

BEVILACQUA, Gabriela Dias; COUTINHO-SILVA, Robson. O ensino de Ciências na $5^{\mathrm{a}}$ série através da experimentação. Ciências e Cognição, v. 10, p. 84-92, 2007.

CASTAMAN, Ana Sara; Vieira, MARILANDI Maria Mascarello. Formação continuada de professores da educação profissional - Continuing education teacher education professional. regae: revista de gestão e avaliação educacional, v. 2, p. 7-15, 2013.

CHASSOT, Áttico. Para que(m) é útil o ensino? .2 ed. Canoas: EdULBRA, 2004.

CHAVES, Jossuele Maria Fagundes; HUNSCHE, Sandra. Atividades experimentais demonstrativas no ensino de Física: panorama a partir de eventos da área. Universidade Federal do Pampa. Rio Grande do Sul, 2014.

DIESEL, Aline; BALDEZ, Alda Leila Santos; MARTINS, Silvana Neumann. Os princípios das metodologias ativas de ensino: uma abordagem teórica. Revista Thema, v. 14, n. 1, p. 268-288, 2017.

FERREIRA, Luiz Henrique; HARTWIG, Dácio Rodney; OLIVEIRA, Ricardo Castro de. Ensino experimental de química: uma abordagem investigativa contextualizada. Química nova na Escola, v. 32, n. 2, p. 101-106, 2010.

FREITAS FILHO, João Rufino de; ÂNGELO, José Henrique Berto; BEZERRA, Janieire Dorlamis Cordeiro; LIRA, Camila Soledade de; ANDRADE, Suelâeny Aparecida de; SILVA, Ivoneide Mendes da; Souza Filho, João Sales de. Laboratório ambulante de química: instrumento de extensão universitária. Rev.Ciênc. Ext. v.8, n.1, p.82-97, 2012.

GALIAZZI, Maria do Carmo.; Gonçalves, Fábio Peres. A natureza pedagógica da experimentação: uma pesquisa na licenciatura em Química. Química Nova, v.27, n.2, p.326331, 2004. 
GIOPPO, Christiane; Scheffer, Elizabeth Weinhardt. O.; Neves, Marcos C. Danhoni. O ensino experimental na escola fundamental: uma reflexão de caso no Paraná. Educ. rev. [online]. 1998, n. 14, pp.39-57. ISSN 0104-4060. http://dx.doi.org/10.1590/0104-4060.180.

GIORDAN, Marcelo. O papel da experimentação no ensino de ciências. Química Nova na Escola, 10(10), 43-49.

LIMA, Gabriel Henrique de; SILVA, Ricardo Sérgio da; ARANDAS, Maria Juliana Gomes; LIMA JÚNIOR, Nivaldo Bernardo de; CÂNDIDO, José Hyrlleson Batista; SANTOS,

Katharine Raquel Pereira dos. O uso de atividades práticas no ensino de ciências em escolas públicas do município de Vitória de Santo Antão- PE. Rev. Ciênc. Ext. v.12, n.1, p. 19-27, 2016.

LOPES, Fernando de Carvalho. Imaginário, Arte e Alquimia: itinerários para uma educação da sensibilidade. Religare (UFPB), v. 10, p. 152-163, 2013.

LUCENA, Guilherme Leocádio; SANTOS, Vandeci Dias dos; SILVA, Afrânio Gabriel da. Laboratório virtual como alternativa didática para auxiliar o ensino de química no ensino médio. Revista Brasileira de Informática na Educação, vol. 21, n. 2, p. 27-37, 2013.

\section{MALDANER, Otavio Aloisio. A Formação Inicial e Continuada de Professores de} Química - Professores /Pesquisadores. Ijuí: UNIJUÍ, 2003.

MARCONI, Marina de Andrade; LAKATOS, Eva. Técnicas de Pesquisa. 7 ed. São Paulo: Atlas, 2010.

MORTIMER, Eduardo Fleury.; MACHADO, Andréa Horta. Química. Volume 1. Primeiro ano do Ensino Médio. -São Paulo: Scipione, 2016.

NOVAIS, Vera Lúcia Duarte de; ANTUNES, Murilo Tissoni. Vivá: Química: volume 2: ensino médio/ Curitiba: editora Positivo, 2016. (Coleção Vivá). ISBN: 978854670800-0 (manual do professor).

OLIVEIRA, Christian Santos; CUNHA, Márcia Cristina; AFFONSO, Ana Lúcia Suriani. Avaliação do Desempenho dos Alunos no Curso pré-Vestibular Unicentro na Disciplina de Química. In: III SIEPE - Semana de Integração Ensino, Pesquisa e Extensão, 2013, Guarapuava. Anais da Semana de Integração Ensino, Pesquisa e Extensão. Guarapuava: Unicentro, 2013. v. 2.

OLIVEIRA, Jane Raquel Silva de. Contribuições e Abordagens das Atividades Experimentais no Ensino de Ciências: reunindo elementos para a prática docente. Acta Scientiae (ULBRA), v. 12, p. 139-153, 2010.

PRAÇA, Fabíola Silva Garcia. Metodologia da Pesquisa Científica: Organização Estrutural e os Desafios para Redigir o Trabalho de Conclusão. Diálogos Acadêmicos, v. 8, p. 72-87, 2015.

SANTOS, Bárbara Cristina Dias; FERREIRA, Maira. Ensino de Química em um Curso de Educação Popular preparatório para o ENEM. In: XVIII Encontro Nacional de Ensino de 
Química (ENEQ), 2016, Florianópolis. Anais do XVIII Encontro Nacional de Ensino de Química (ENEQ), 2016.

SANTOS, Cristiano Alexandre dos. Identidade profissional do professor do Cursinho Garra de Goiânia. 2004. 227 f. Dissertação (Mestrado em Ciências Humanas) - Pontifícia Universidade Católica de Goiás, Goiânia, 2004.

SCHWARTZMAN, Simon. O ensino médio no Brasil é formal, acadêmico, voltado para o vestibular. Não atende jovens com outros interesses. Revista Ensino Superior Unicamp, Ano 1, n. 2, 2010, p.16-25.

SILVA, Vinícius Gomes. A importância da experimentação no ensino de química e ciências. Trabalho de Conclusão de Curso - TCC. Universidade Estadual Paulista. Bauru, 2016.

SILVA, Roberto Ribeiro da.; MACHADO, Patrícia Fernandes Lootens. Experimentação no ensino médio de química: a necessária busca da consciência ético-ambiental no uso e descarte de produtos químicos - um estudo de caso. Ciência \& Educação, v.14, n.2, p.233-249, 2008.

STADLER, João Paulo; HUSSEIN, Fabiana Roberta Gonçalves e Silva; MARQUES, Carlos Alberto. Questões de Química do novo ENEM com potencial para abordagem sócio científica. Estudos em Avaliação Educacional, v. 30, n. 75, p. 780-798, 2020.

TAPIA, Jesús Alonso.; FITA, Enrique Cartula. A motivação em sala de aula: o que é, como se faz? 7. ed. São Paulo: Loyola, 2006.

TONDIN, Celso Francisco; SANTOS, Larissa Medeiros Marinho dos; MAGALHÃES, Deruchette Danire Henrique; PEREIRA, Jacqueline Danielle. Prática pedagógica e relação professor-aluno em cursinhos. PSI UNISC, v. 2, p. 90-104, 2017.

USBERCO, João; SALVADOR, Edgard. Conecte Química. São Paulo: Saraiva, 2011.

VARGAS, Hustana Maria. (2010). Sem perder a majestade: "profissões imperiais" no Brasil. Estudos de Sociologia, 15(28), 107-124.

WHITAKER, Dulce Consuelo Andreatta. Rev. bras. orientac. prof, São Paulo, v. 11, n. 2, p. 289-297, dez. 2010. Disponível em:

http://pepsic.bvsalud.org/scielo.php?script=sci_arttext\&pid=S167933902010000200013\&lng=pt\&nrm=iso. Acesso em 29 jun. 2018.

YIN, Robert. K. Estudo de Caso: planejamento e métodos. Tradução: Cristhian Matheus Herrera. 5. ed. Porto Alegre: Bookman, 2015.

Recebido em: 10 de junho de 2020.

Aprovado em: 27 de agosto de 2020. 